\title{
TRANSFERRING SURGICAL STRESS
}

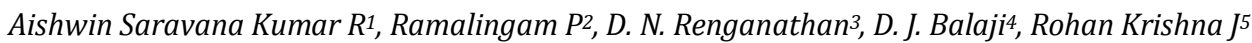

1Associate Professor, Department of General Surgery, Karpagam Faculty of Medical Sciences and Research, Coimbatore. 2 Associate Professor, Department of General Surgery, Karpagam Faculty of Medical Sciences and Research, Coimbatore. 3 Professor, Department of General Surgery, Karpagam Faculty of Medical Sciences and Research, Coimbatore.

4 Postgraduate Student, Department of General Surgery, Coimbatore Medical College (GS).

${ }^{5}$ Senior Resident, Department of General Surgery, Karpagam Faculty of Medical Sciences and Research, Coimbatore.

ABSTRACT
BACKGROUND
There is a routine practice of getting informed written consent in patients undergoing any medical procedure, especially surgical
procedure. In case of high-risk surgery, we routinely get an informed high-risk written consent. We get consent from both the patient
and the patient's close and reliable relatives. Patients routinely agree and give consent to all medical procedures, but actually most
of the patients are unaware of the condition of patient or the disease severity and its complications from which he or she is suffering
from at the time of giving consent. When something grave happens to the patient, the entire blame is on the doctor that the patient's
relatives were unaware of the condition of the patient and there is lot of stress to the doctor who is treating a high-risk patient and
declaring death. In order to modify this, in this study we took one of the patient's close and reliable attender inside the operating
room to visualise the pathology in person and explained them in detail the condition of the patient. We suggest that by this method,
the stress to the doctors regarding risks to the patient is reduced and they need not explain each and every one about the condition
of the patient. We will continue to take attenders inside operating room and explain the condition in high-risk cases.

\section{KEYWORDS}

Consent, Stress, Relatives.

HOW TO CITE THIS ARTICLE: Kumar ASR, Lingam RP, Renganathan DN, et al. Transferring surgical stress. J. Evolution Med. Dent. Sci. 2018;7(07):929-931, DOI: 10.14260/jemds/2018/211

\section{BACKGROUND}

There is lot of stress to the surgeon when he or she is operating a high-risk case on the outcome of the patient. More than that there is more stress when explaining poor outcome to the patient's relatives or attenders. Most often the patient's relatives just sign the informed written consent without knowing the full details of the surgery, condition of patient, nature of disease and the complications that might happen. $(1,2,3)$ When any complications occur, the surgeon has to answer lot of questions from the patient's attenders and invariably has a lot of stress. In order to prevent this, in this study we took the patient's attenders (Responsible, close relatives) inside the operating room and explained them in detail the condition of the patient, visualise the pathology of the patient in person. We suggest that by this method the stress to the doctors regarding risks to the patient is reduced and they need not explain each and every one about the condition of the patient.

\section{MATERIALS AND METHODS}

\section{Study Area}

Coimbatore Medical College Hospital [CMCH], Coimbatore.

\section{Study Population}

Patients undergoing emergency surgery at $\mathrm{CMCH}$.

'Financial or Other Competing Interest': None.

Submission 27-12-2017, Peer Review 01-02-2018,

Acceptance 07-02-2018, Published 12-02-2018.

Corresponding Author:

Dr. Aishwin Saravana Kumar R,

Associate Professor,

Department of General Surgery,

Karpagam Faculty of Medical Sciences and Research,

Coimbatore.

E-mail:drrengs@gmail.com

DOI: $10.14260 /$ jemds $/ 2018 / 211$

\section{Study Period}

3 months from October 2016 to December 2016.

\section{Sample Size}

20 patients undergoing emergency surgery at $\mathrm{CMCH}$.

\section{Methodology}

The patients presenting to the emergency department (Casualty) in Department of General Surgery were examined clinically and all investigations were done to arrive at the diagnosis. Emergency surgery planned and informed written high-risk consent was also obtained from the patient and the attenders or the relatives. $(4-5)$ During the surgery in the operating room, the relative or the attender will be explained about the sterile precautions in the operating room and appropriate OT dress will be given and will be allowed inside the operating room accompanied by two junior doctors. The surgeon will explain the disease condition, which the patient's relative visualise in person. We will show the attender the various pathology like bowel perforation or gangrenous bowel segment etc. We explain about the type of surgical procedure and also adverse outcomes that may occur during or after surgery.

In our study, we have so far introduced 20 patient's attenders inside the operating room as mentioned above and explained to them in detail about the various proceedings of the surgical procedure and the attenders have gotten a chance to visualise the real condition of the patient's disease.

Out of 20 patient attenders, one of the patient's attender had a vasovagal attack and was escorted out of the operating room immediately and was treated appropriately without any complications.

All the patient's attenders were very much satisfied with our treatment and our effectiveness in explaining the appropriate condition of the patient and they had no problems in understanding the situation when we explained the 
complications which occurred during the post-operative period and were not finding faults with our treatment since they had already visualised the current status of the patient in the operating room.
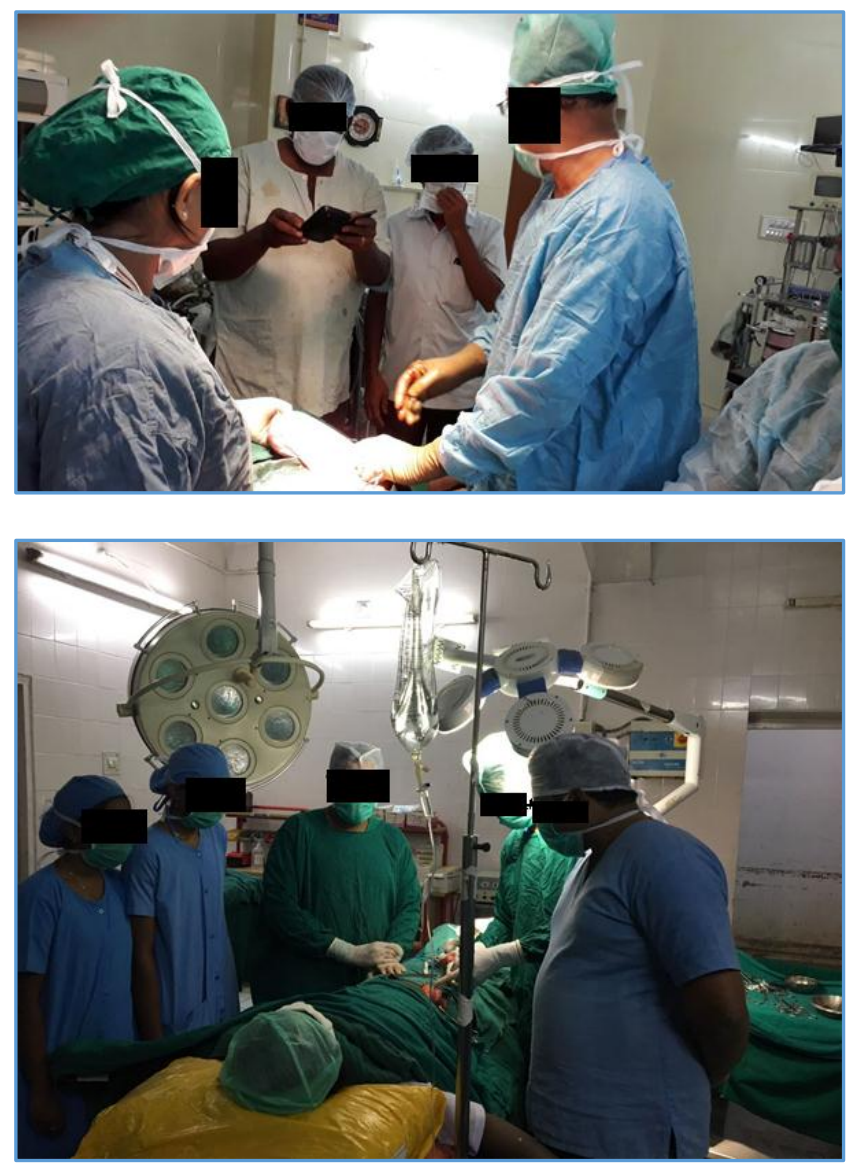

\section{RESULTS}

From October 2016, we have so far taken 20 patient's attenders inside the operating room. Out of 20 patients, 5 patients had expired due to various surgical and medical complications during the post-operative period. In spite of the demise of the patient, the patient's attenders were very much satisfied about our treatment approach, especially taking them inside the operating room and explaining the condition and did not produce any problems legally or non-legally within the hospital and had developed a special attachment to the hospital which had made them feel the experience which doctors undergo in a day-to-day practice. $(6,7,8)$

\section{DISCUSSION}

There is a routine practice of getting informed written consent in patients undergoing any medical procedure, especially surgical procedure in case of high-risk surgery we routinely get an informed high-risk written consent. We get consent from both the patient and the patient's relatives. Patients routinely agree and give consent to all medical procedures, but actually most of the patients are unaware of the condition of the patient nor the disease severity from which he or she is suffering from at the time of giving consent. When something grave happens to the patient, the entire blame is on the doctor, that the patient's relatives were unaware of the condition of the patient and there is lot of stress to the doctor who is treating a high-risk patient.
We would like to introduce to the developing new methodology for reducing the stress of the operating doctor and to increase the patient-doctor relationship without any hassles. We have found that from our study that by this method the surgical stress between the doctor and patient's attenders is reduced to a great extent about the prognosis of the patient's condition. (9-10) $^{-10}$

(In our experience we had come across a patient of Carcinoma Stomach, which was identified to be operable preoperatively by investigations and we proceeded with surgery, but intraoperative we found that the carcinoma stomach was infiltrating into the pancreas so we were not able to proceed with a definitive procedure. Immediately, ${ }^{(11-12)}$ we brought the patient's attender inside the operating room, explained and showed him the reason for inoperability and explained that we will proceed with a palliative procedure which was better for the patient's outcome and was agreed by the attender.)

\section{CONCLUSION}

From our study, it is found that rather than just getting an informed written consent the real visualisation of the patient's condition gives better acceptance by the patient's attenders regarding the disease of the patient.

By this methodology the mental stress of the surgeons in dealing with the patient's attenders is reduced by a great extent, which in turn results in a better doctor-patient relationship and provides the patient's attenders with a grief support system which helps them cope better in regards to any complications that might arise in the post-operative period.

\section{REFERENCES}

[1] California Appellate Court. Salgo v Leland Stanford Jr University Board of Trustees. Oct 22, 1957.

[2] Faden RR, Beauchamp TL. A history and theory of informed consent. New York: Oxford University Press 1986.

[3] Jones JW, McCullough LB, Richman BW. Informed consent: it's not just signing a form. Thorac Surg Clin 2005;15(4):451-60.

[4] Greenfield S, Kaplan S, Ware JE. Expanding patient involvement in care. Effects on patient outcomes. Ann Intern Med 1985;102(4):520-8.

[5] Stewart MA. Effective physician-patient communication and health outcomes: a review. CMAJ 1995;152(9):1423-33.

[6] Davis RE, Jacklin R, Sevdalis N, et al. Patient involvement in patient safety: what factors influence patient participation and engagement? Health Expect 2007;10(3):259-67.

[7] Chen JY, Tao ML, Tisnado D, et al. Impact of physician-patient discussions on patient satisfaction. Med Care 2008;46(11):1157-62.

[8] Iversen MD, Daltroy LH, Fossel AH, et al. The prognostic importance of patient pre-operative expectations of surgery for lumbar spinal stenosis. Patient Educ Couns 1998;34(2):169-78.

[9] Levinson W, Roter DL, Mullooly JP, et al. Physicianpatient communication. The relationship with malpractice claims among primary care physicians and surgeons. JAMA 1997;277(7):553-9. 
[10] Braddock CH, Fihn SD, Levinson W, et al. How doctors and patients discuss routine clinical decisions. Informed decision making in the outpatient setting. J Gen Intern Med 1997;12(6):33945.
[11] Edwards WS, Yahne C. Thomas G. Orr Memorial Lecture. Surgical informed consent: what it is and is not. Am J Surg 1987;154(6):574-8.

[12] Lidz CW, Appelbaum PS, Meisel A. Two models of implementing informed consent. Arch Intern Med 1988;148(6):1385-9. 